\title{
Acquisition of stimulus matching without the use of non-matching stimuli '
}

\author{
RICHARD W. MALOTT, MARILYN KAY MALOTT AND JOHN SVINICKI \\ WESTERN MICHIGAN UNIVERSITY
}

$A$ basic free operant procedure was used to study stimulus matching of color with pigeons in order to determine whether matching could be established with four different combinations of matching colors and no nonmatching stimuli present during training. Subsequent generalization tests using both matching and nonmatching stimulus combinations showed that the matching concept had been obtained.

Recently, a one-key experimental chamber was used by Malott \& Malott (1967) for stimulus matching. Matching behavior was obtained without the use of nonmatching stimuli in training. The generalization gradients showed more responding in the presence of the matching combinations than the nonmatching combinations of colors. The results demonstrated that stimulus control by a complex relational concept can be established without using an S- (nonreinforced example of the stimuli outside the concept).

The data, while indicating generalized matching, were not as clear as was desired. The present study was undertaken to obtain more data on the learning of matching-to-sample without the use of stimuli in the presence of which responses are extinguished (S-). The source of data was generalization tests and the gradients that result from such a procedure. This study was a continuation of the previously mentioned study. Method

The Ss were six, naive White Carneaux barren hen pigeons, obtained from Paletto Pigeon Farm. They were maintained at $70 \%$ of their free-feeding weights.

The test chamber was a Lehigh Valley Electronics pigeon chamber (No. 1519c) without a houselight. Two colors could be projected simultaneously, each color on half of the response key. A 1-1/4 in. black vertical stripe divided the two sections of the key.

Using standard operant conditioning procedures, the Ss were shaped to peck a response key and were stabilized on a random-interval $64 \mathrm{sec}$ schedule of reinforcement (cf., Farmer, 1963). The stimulus equivalence training consisted of presenting four stimuli: red-red; yellow-yellow; blue-blue; and violet-violet. The change from one $S+$ to another occurred after each reinforcement, and the sequence was $R R, Y Y, B B, V V$, RR, YY, etc. There were no S-'s.

After achieving a relatively stable rate of responding, each $\mathrm{S}$ was given a generalization test in extinction, once per week for the next five weeks, to determine whether or not $\mathrm{S}$ had learned the concept of matching. The sixth generalization test was given three weeks after the fifth one because extinction had been occurring too rapidly during the tests. The generalization test was an extinction session in which two of the S+'s used in training were presented along with the two combinations of nonmatching colors. These four stimuli were randomly presented and rates of responding to each were recorded. Using the highest response rate for a given $S$ as a maximum, percentages of this number were computed, recorded, and graphed in the form of a generalization gradient.

\section{Definition of Matching Behavior}

When matching behavior occurs, each of the matching stimuli will be responded to more than either of the nonmatching ones. The interest here is not whether one stimulus is higher than another, but rather that two matching stimuli are higher than two nonmatching ones. For example, if the stimuli are $R R, B R, R B$, and $B B$, two of the possible orders are: RR highest, $B B$ second, RB third, and BR lowest; or $B B$ highest, $R R$ second, $B R$ third, and $R B$ fourth, or lowest. As far as matching behavior is concerned, these two combinations are the same. That is, each matching stimulus is higher than either of the nonmatching ones.

Results and Discussion

The results of the six generalization tests are summarized in Table 1. This may be read as follows:

Table 1

Percentages of maximum response rate for each $S$ on each generalization test. (Blank spaces indicate that there were not enough responses to establish a reliable gradient. An "*" indicates a matching gradient resulted from that test for the S. The symbols above each column indicate the colors of the stimulus.)

\begin{tabular}{|c|c|c|c|c|c|c|c|c|c|c|c|c|c|c|c|c|c|c|c|c|c|c|c|c|}
\hline \multirow[b]{3}{*}{ Subjects } & \multicolumn{24}{|c|}{ Tests } \\
\hline & \multicolumn{4}{|c|}{1} & \multicolumn{4}{|c|}{2} & \multicolumn{4}{|c|}{3} & \multicolumn{4}{|c|}{4} & \multicolumn{4}{|c|}{5} & \multicolumn{4}{|c|}{6} \\
\hline & $\mathrm{vV}$ & RV & VR & RR & BB & YB & BY & $Y Y$ & $Y Y$ & RY & YR & RR & $\mathrm{VV}$ & BV & VB & BB & vV & $\mathrm{YV}$ & VY & $Y Y$ & RR & BR & RB & BB \\
\hline A-4-1 & 100 & 72 & 69 & 66 & 66 & 61 & 57 & $100^{*}$ & & & & & 100 & 84 & 56 & 69 & 68 & 85 & 26 & 100 & 96 & 76 & 98 & 100 \\
\hline A-4-2 & 100 & 93 & 74 & 75 & 100 & 81 & 63 & $83^{*}$ & 88 & 76 & 85 & $100^{*}$ & 58 & 75 & 52 & 100 & 86 & 96 & 36 & 100 & 75 & 79 & 99 & 100 \\
\hline A-4-3 & 98 & 100 & 99 & 93 & 93 & 91 & 99 & 100 & 100 & 83 & 76 & 76 & 96 & 100 & 85 & 92 & 89 & 84 & 83 & $100^{*}$ & 99 & 78 & 96 & $100^{*}$ \\
\hline A- $4-4$ & 96 & 100 & 85 & 81 & 83 & 91 & 86 & 100 & 99 & 89 & 80 & $100^{*}$ & & & & & 60 & 100 & 55 & 75 & 100 & 82 & 81 & $88^{*}$ \\
\hline A-4-5 & 83 & 100 & 99 & 98 & 91 & 86 & 86 & $100^{*}$ & 88 & 84 & 81 & $100^{*}$ & 83 & 100 & 69 & 93 & 74 & 68 & 36 & $100^{*}$ & 100 & 83 & 83 & $86^{*}$ \\
\hline A-4-6 & 90 & 66 & 78 & $100^{*}$ & 100 & 22 & 21 & $88^{*}$ & & & & & & & & & & & & & 100 & 23 & 31 & $89^{*}$ \\
\hline
\end{tabular}


For Test 1, the colors used were violet and red. Subject A-4-6 was the only one that yielded a gradient that demonstrated matching behavior. For three Ss (A-4-3, $A-4-4$, and $A-4-5)$, a nonmatching stimulus was highest on the gradient. The other two Ss (A-4-1 and A-4-2) had peaks on a matched stimulus.

A total of 31 gradients were obtained which met the criterion of more than 50 responses occurring at the maximum. Fourteen of these gradients indicated stimulus matching. The probability of obtaining 14 or more matching gradients out of 31 total gradients is less than .001.

These data indicate that an abstract concept or relational discrimination can be formed without discrimination training between classes of concepts. The extent to which concepts, other than matching and nonmatching, may be formed without explicit discrimination training remains to be determined.

\section{References}

FARMER, J. Properties of behavior under random interval reinforcement schedules. J. exp. Anal. Behav., 1963, 6, 607-616.

HEINEMANN, E. G., \& RUDOLPH, R. L. The effects of discriminative training on the gradients of stimulus-generalization. Amer. J. Psychol, $1963,76,653-658$.

MALOTT, R. W., \& MALOTT, MARILYN K. An analysis of stimulus matching in terms of stimulus generalization. Submitted for publication, 1967.

Note

1. This research was supported by Public Health Service Grant MH $13178-01$. 